\title{
O Papel da Moeda nas Teorias do Desenvolvimento Desigual: uma Abordagem Pós-Keynesiana
}

\section{The Role of Money in the Theory of Unequal Economic Development: a Post Keynesian Approach}

Ana Tereza Lanna Figueiredo ${ }^{1}$

Resumo: A teoria do desenvolvimento desigual ocupa-se de investigar por que algumas regiões e/ou países crescem mais que outros. Na tentativa de resolver essa problemática, os estudiosos do assunto não consideraram explicitamente a moeda como fator importante. Entretanto, segundo a abordagem pós-keynesiana, a moeda não é neutra, exercendo papel central na determinação da dinâmica de acumulação da economia. Este artigo visa identificar se a teoria do desenvolvimento desigual incorpora a idéia da não-neutralidade da moeda no processo de desenvolvimento de um país ou região. A partir da análise empreendida, pode-se concluir que, apesar de os estudos de Rosenstein-Rodan (1943), Nurske (1955), Hirschman (1961) e Myrdal (1960) não explicitarem o papel da moeda nesse processo, a maior parte deles o fazem implicitamente, ao introduzirem a incerteza como fator fundamental na tomada de decisão dos agentes econômicos.

Palavras-chave: Desenvolvimento desigual. Moeda. Incerteza.

Abstract: The theory of unequal economic development aims at understanding why some regions and/or countries grow more than others. In an attempt to solve this problem, scholars have not explicitly considered money as an important factor. However, according to a post-Keynesian approach, money is not neutral and it has a major role in determining the economy's dynamic. This paper purports to identify if the theory of unequal economic development incorporates the idea of non neutrality of money in the developing process of a region. It may be concluded that, despite the fact the theories developed by Rosenstein-Rodan (1943), Nurske (1955), Hirschman (1961), and Myrdal (1960) do not make explicit the role of money in this process, most of them imply it as they introduce uncertainty as a crucial factor in determining agents' behaviour.

Keywords: Unequal economic development. Money. Uncertainty.

JEL Classification: E12; O20; O40.

1 Professora Assistente da PUC Minas. Doutoranda em Economia pelo CEDEPLAR/UFMG. E-mail: lanna@pucminas.br 


\section{Introdução}

A teoria do desenvolvimento desigual ocupa-se de uma questão central: por que alguns países e/ou regiões crescem mais que outros? $\mathrm{Na}$ tentativa de resolver essa problemática, os estudiosos do assunto não consideraram explicitamente a moeda como fator importante nesse cenário. Entretanto, segundo a abordagem pós-keynesiana, a moeda não é neutra. Ela exerce papel central no processo decisório dos agentes econômicos. Destarte, é fundamental na determinação da dinâmica de acumulação da economia, não devendo, pois, ser negligenciada.

Este trabalho objetiva identificar se a teoria do desenvolvimento desigual, nas suas duas versões - crescimento equilibrado e crescimento desequilibrado - incorporam, ainda que implicitamente, a ideia da não neutralidade da moeda no processo de desenvolvimento de um país ou região.

Para tanto, faz-se necessário expor, em linhas gerais, as principais ideias que permeiam o pensamento pós-keynesiano e as contribuições fundamentais de Rosenstein-Rodan (1943), Ragnar Nurske (1955), Albert Hirschman (1961) e Gunnar Myrdal (1960) para a teoria do desenvolvimento desigual. Pretende-se, a partir daí, estabelecer uma associação entre os fundamentos das respectivas teorias no que diz respeito à moeda. Esses dois temas serão abordados nos itens 2 e 3 . Com o objetivo de contribuir para o avanço do debate, o item 4 apresenta alguns estudos recentes de autores pós-keynesianos que evidenciam a importância da moeda para explicar as disparidades regionais. Por fim, são apresentadas as considerações finais.

\section{Incerteza e Moeda: a Essência da Teoria Pós-Keynesiana}

Os pós-keynesianos consideram a moeda como parte integral do processo econômico, não sendo possível distinguir claramente o lado monetário do lado real da economia, contrariamente à visão dos neoclássicos. ${ }^{2}$

Seguindo Keynes, partem desde o início de uma economia monetária de produção, que é um conceito definido para descrever uma visão particular das regras de funcionamento de um sistema capitalista moderno. Em uma economia monetária, as firmas produzem não para adquirirem mais bens ou para atender às necessidades dos consumidores (como no modelo neoclássico), mas para auferir mais renda, mais riqueza.

2 Para os neoclássicos, existe uma clara dicotomia entre o lado real e o monetário da economia. Segundo a sua concepção, a moeda é apenas um meio de troca, mero instrumento para facilitar as transações. Assim, o equilibrio é garantido na economia real, antes de qualquer alusão à esfera monetária. A moeda é assim neutralizada. Não tem valor absoluto, pois não produz nada por si mesma nem é consumida por si própria. Sua utilidade é apenas indireta (MOLLO, 2003). 
Uma de suas principais características é a importância atribuída ao processo de tomada de decisão em um ambiente de incerteza (FEIJÓ, 1999). O destaque é que os economistas pós-keynesianos trabalham com a hipótese de formação de expectativas sob incerteza não-probabilística. ${ }^{3}$ Carvalho (1992) ressalta que o que realmente importa para Keynes e para os pós-Keynesianos para explicar a decisão de investir é o estado das expectativas de longo prazo, e não as de curto prazo, pois aquelas são as forças que orientam a ação dos agentes.

Tal fato significa a impossibilidade, a priori, de determinar o quadro relevante de influências que atuarão entre a decisão de implementar um determinado plano e a obtenção de resultados. Segundo Feijó (1999), uma vez que um projeto começa a ser implementado, não se consegue revertê-lo sem custos. Isso torna as decisões de produzir e investir irremediavelmente especulativas.

O funcionamento do sistema econômico depende, assim, da expectativa dos agentes sobre o futuro e dos efeitos que essa visão tem sobre a retenção de moeda (MOLLO, 2003). Ressalte-se que, sob incerteza, reter moeda como um ativo pode ser um ato racional. Na teoria de Keynes, a moeda não é demandada apenas por conveniência; pode ser demandada por si mesma, por ser o mais líquido dos ativos. Ela pode indefinidamente funcionar como reserva de valor - ou seja, a moeda pode não ser gasta indefinidamente. Quando as perspectivas ou as expectativas sobre o futuro são pessimistas, aumenta-se o desejo de liquidez e a moeda torna-se o ativo mais atraente. Tal fato implica a possibilidade de os fatores de produção ficarem ociosos (FEIJÓ, 1999). Para os neoclássicos, por sua vez, a moeda tem o atributo de reserva de valor somente no curto prazo. Em algum momento, entretanto, ela será gasta - isso valida a Teoria Quantitativa da Moeda, assim como a Lei de Say.

Conforme Dow e Rodrigues-Fuentes (2003), esse fato pontuado pelos pós-Keynesianos reflete-se no aumento da preferência pela liquidez dos agentes, que é um indicador da quantidade de moeda que desejam reter. Mudanças nesta, devido ao maior ou menor grau de confiança na economia, abrem a possibilidade para alterações endógenas na renda, uma vez que levam a flutuações na demanda efetiva. Assim, a moeda não é neutra na economia.

De acordo com os pós-keynesianos, a moeda entra no sistema econômico, especialmente, através do crédito suprido pelo sistema bancário, em resposta à demanda, não sendo, portanto, exógena. Assim, ao invés de determinar o nível geral de preços, o crédito permite a validação do investimento.

3 Entende-se aqui que incerto é o fenômeno para o qual não é possível mensurar sua probabilidade - ver Davidson (1982-83; 1995), Dow (1995) e Crocco (1999). 
No que se refere à relação entre oferta de crédito e poupança, os póskeynesianos não concordam que o crédito deva ser lastreado pela poupança que financiaria o investimento. Em uma economia com um sistema de crédito desenvolvido, a poupança não precisa preceder o investimento. ${ }^{4}$ Além disso, mesmo que ela exista, no sentido de não consumo, nada garante que a oferta de crédito se expandirá. O que importa é a preferência pela liquidez manifesta pelo público (comprando ativos financeiros) ou pelos bancos (liberando empréstimos em condições satisfatórias) (MOLLO, 2003).

Conforme sintetizado por Crocco et al. (2003), a análise pós-keynesiana aborda tanto o lado da demanda quanto o da oferta de crédito no mercado regional. Do ponto de vista da demanda por crédito, a decisão de portfólio dos indivíduos será determinada pela respectiva preferência pela liquidez. Quanto maior ela for, menor a demanda por crédito e maior a posição em ativos líquidos desses agentes. Pelo lado do sistema bancário, por sua vez, a preferência pela liquidez afeta a disposição dos bancos em emprestar dinheiro na região. Caso esses possuam expectativas negativas em relação ao desempenho econômico local, a preferência pela liquidez será elevada e a oferta de crédito ali restringida.

Os bancos possuem, assim, papel fundamental e complexo no sistema econômico, não sendo meros intermediários entre investidores e poupadores. Como agentes ativos, podem forçar o uso de recursos para a compra de bens de capital, que por sua vez contribuem para o desenvolvimento da economia.

Por fim, cabe ressaltar que, assim como Keynes, os economistas póskeynesianos defendem um papel permanente para o governo na economia. Esse deve adotar políticas econômicas dirigidas a aumentar o nível de demanda agregada, a fim de criar um ambiente estável e seguro, que estimule os empresários a realizar novos investimentos. Segundo eles, o nível de emprego depende dos determinantes da demanda agregada, especialmente da decisão de investimento dos empresários. Em outras palavras, a política econômica deve procurar afetar o investimento privado global, criando um clima seguro que estimule escolhas mais arriscadas em vez de acumular ativos líquidos. Assim, a boa política para eles é aquela que induz os agentes a investirem em ativos de capital (investimento novo). (DE PAULA, 2004; OREIRO; DE PAULA, 2005).

\section{Teorias do Desenvolvimento Desigual}

A teoria do desenvolvimento desigual nega que o processo de crescimento econômico seja contínuo, cumulativo. Segundo seus teóricos,

4 Para um melhor entendimento dessa dinâmica, ver KEYNES (1971a, 1971b, 1971c). 
não existem etapas a serem cumpridas pelos países e/ou regiões para se chegar ao desenvolvimento. Na verdade, assumem que o desenvolvimento baseia-se na ideia de descontinuidade, desequilíbrio. Essa situação pode advir tanto da indivisibilidade do capital (por exemplo, no setor de infra-estrutura - energia, transporte -), como também da incerteza que permeia o ambiente econômico e afeta negativamente a tomada de decisão empresarial. O Estado, então, deve assumir um papel fundamental no estímulo ao investimento e, em última instância, na promoção do crescimento.

Entretanto, apesar dos argumentos comuns, surgiram os modelos de crescimento equilibrado e os de crescimento desequilibrado, que levam a diferentes conclusões acerca do que deve ser feito para alcançar o desenvolvimento, conforme será exposto a seguir.

\subsection{Crescimento Equilibrado - as Formulações Básicas de Rosenstein-Rodan (1943) e Ragnar Nurske (1955)}

\subsubsection{Rosenstein-Rodan}

Rosenstein-Rodan (1943), ao analisar o problema da industrialização da Europa Oriental e Sul-Oriental (ambas as áreas deprimidas), indicou caminhos para se alcançar o desenvolvimento econômico.

Segundo o autor, são três os principais desafios que um país ou uma região deprimida deve enfrentar: a oferta escassa de capital, especialmente de capital social básico; a relativa ausência de complementaridade de demanda; e a oferta reduzida de poupança (mercado de capitais inexpressivo).

A solução colocada por ele para resolver esses três problemas simultaneamente seria a realização de um grande pacote de investimentos, a ser promovido pelo Estado, por meio da criação do Truste Industrial da Europa Oriental (TIEO). ${ }^{5}$

O referencial teórico que embasa o trabalho do autor é muito impreciso. Ele combina conceitos neoclássicos - Lei de Say e curva de oferta de poupança - com elementos keynesianos, tais como a incerteza e o papel desempenhado pela moeda (LEMOS, 1988).

Feita essa ressalva, cabe aqui apontar que, apesar de não mencionar explicitamente em seu estudo, o autor leva-nos a concluir que a moeda não é neutra. Rosenstein-Rodan (1943) coloca claramente que a principal

5 Essa denominação deveria ser alterada, segundo o autor, para evitar associações desagradáveis com o termo "truste". Uma opção seria usar o termo "Corporação Industrial" ou "Companhia Holding". 
força propulsora do investimento é a expectativa de lucro do empresário individual. Essa última, conforme os economistas neoclássicos, baseia-se na experiência do passado. Entretanto, segundo o autor, essa experiência do passado é irrelevante quando se trata de transformar toda a estrutura econômica de uma região - que é o que se pretende com a criação do Truste.

Sendo assim, o conhecimento do empresário individual sobre o mercado é insuficiente. Conforme Rosenstein-Rodan (1943), esse seria um argumento em favor da criação do TIEO. O Conselho de Planejamento da empresa disporia de mais conhecimento sobre o mercado, reduzindo as incertezas.

Nesse sentido, está em concordância com o pensamento pós-Keynesiano, que sustenta que o passado não é um bom guia para se pensar no futuro. Segundo esses teóricos, as decisões de investimento baseiam-se, ao invés, nas expectativas de longo prazo dos empresários. Essas, por sua vez, pouco têm a ver também com as condições correntes da economia.

Tal fato gera incerteza que pode influenciar negativamente a ação empresarial, caso a estimativa de risco subjetivo do investidor seja superior ao risco objetivo. Esse tipo de raciocínio somente é válido se se assume que a moeda desempenha algum papel no sistema econômico.

Frente à incerteza, os agentes econômicos, especialmente os empresários e os bancos, aumentam sua preferência pela liquidez. Firmas podem preferir manter ativos líquidos a investir em bens de capital e bancos podem escolher direcionar recursos para o circuito financeiro ao invés do circuito industrial. Isso abre a possibilidade de ocorrerem falhas de demanda efetiva.

Rosenstein-Rodan (1943) pondera que a incerteza pode aumentar ainda mais devido à interdependência existente entre as diversas decisões de investimento por parte dos agentes. Dessa forma, propõe a realização de um grande pacote de investimento, patrocinado pelo Estado, que reduziria o risco e, portanto, a incerteza do ponto de vista do investidor individual. Conclui seu raciocínio alegando que, se as áreas internacionais deprimidas tivessem que depender do incentivo normal dos empresários privados para se industrializar, o processo seria bem mais lento e a taxa de investimento na economia seria muito mais baixa, implicando assim em uma menor renda nacional. Acrescente-se também que toda a estrutura econômica da região seria diferente. O investimento distribuir-se-ia em proporções diferentes entre as diversas indústrias e o equilíbrio final estaria abaixo do ótimo que poderia ser alcançado pela construção do TIEO.

\subsubsection{Ragnar Nurske}

A pequenez do mercado interno é tida por Nurske (1955) como o grande obstáculo ao desenvolvimento de um país. Segundo o autor, nos 
países pobres, a produção de bens e serviços para o mercado interno é restringida pelo pequeno tamanho desse mercado, pela falta de poder de compra real, que decorre do baixo nível de produtividade. Assim, não há incentivo para o investimento. Por outro lado, a pequena capacidade de poupar, resultante do baixo nível de renda real, determina uma oferta restrita de capital.

O autor desenvolve sua teoria fundamentada nos princípios neoclássicos. Em seu trabalho, assume explicitamente que a poupança precede o investimento. A oferta de capital em um país é determinada pela sua habilidade e propensão para poupar que, por sua vez, determina o seu montante de investimento.

Segue também a tradição neoclássica ao aceitar a Lei de Say. Segundo o autor, a deficiência de demanda existente nas economias subdesenvolvidas não é uma deficiência de demanda efetiva, no sentido Keynesiano, e sim uma escassez de poder de compra real da população - consequência da reduzida renda real, decorrente em parte da baixa produtividade. De acordo com ele, como não há insuficiência de demanda monetária, não há brecha deflacionária. Ao contrário, observa-se nesses países recorrente tendência inflacionária. Embora baixa, a demanda monetária é excessiva em relação à capacidade de produção. Em sua visão, a oferta cria, sim, sua própria demanda, mas a oferta, no caso, é muito reduzida.

O autor ressalta, entretanto, que a validade da Lei de Say para regiões economicamente atrasadas é restrita. Isso porque, de acordo com ele, a produção de qualquer indústria isolada, recém criada, não cria a sua própria demanda. É pouco provável que as pessoas ocupadas na nova indústria gastem toda a sua renda nos produtos da mesma, dadas as diversas necessidades humanas.

Assim, o estímulo para investir é anulado pela pobreza e a aplicação de capital em uma única linha de produção é desencorajada. É sabido que, de um lado, as descontinuidades técnicas requerem consideráveis "saltos" (investimentos) para a sua superação. Por outro lado, a pequena e inelástica demanda num país de renda baixa tende a tornar arriscados ou completamente falhos esses "saltos" em qualquer tipo de negócio considerado independentemente.

Dessa forma, a expansão econômica não se dá de forma espontânea ou mesmo automática. Ao contrário, conforme afirma Nurske (1955), dentro do sistema existem forças naturais que tendem a fixá-lo em determinado nível. Ressalta, entretanto, que esse círculo vicioso da pobreza não é intransponível.

A aplicação mais ou menos sincronizada do capital a uma ampla escala de indústrias diferentes supera a dificuldade, se existente, advinda do desestímulo ao investimento individual. Com isso, eleva-se o nível geral 
da eficiência econômica e aumenta-se o mercado de forma geral - claro, considerando-se aqui a ideia de equilíbrio inerente à lei clássica dos mercados, qual seja, a lei de Say. Essa estratégia de crescimento equilibrado é capaz de romper o círculo vicioso da pobreza, levando ao desenvolvimento do país. Para o autor, não importa se tal estratégia será levada a cabo pelo governo (por conselhos planificados) ou pelo empresariado. O que importa é a natureza da solução e não a forma que será adotada para se atingi-la.

Nurske (1955), ao elaborar sua teoria fundamentada no arcabouço neoclássico, não confere à moeda nenhum papel no processo de desenvolvimento econômico de um país. Essa é neutra nos seus efeitos na economia real.

\subsection{Crescimento Desequilibrado - as Contribuições de Hirschman (1961) e Myrdal (1960)}

\subsubsection{Albert Hirschman}

De acordo com Hirschman (1961), a teoria do desenvolvimento equilibrado, além de ser impraticável, é também antieconômica. $\mathrm{O}$ autor questiona a viabilidade de empreender-se uma ampla gama de investimento nos diversos setores da economia em um país subdesenvolvido, uma vez que, para tanto, seria necessário dispor de um grande volume de recursos. É sabido, entretanto, que, exatamente nesses países, os recursos apresentam-se bastante escassos. Assim, em contraposição a essa teoria, Albert Hirschman (1961) desenvolveu a teoria do desenvolvimento desequilibrado.

Cabe ressaltar que, em seu trabalho, Hirschman (1961) pressupõe a precedência da poupança sobre o investimento, apresentando assim viés neoclássico. Ele desenvolve a ideia da "habilidade para o investimento", que seria a capacidade de se transformar economias existentes - poupança-em investimento produtivo. Ele pondera que os países desenvolvidos possuem esse atributo. Assim, o investimento ocorre automaticamente toda vez que se disponha de poupança e oportunidade de inversão. Já os países mais atrasados economicamente, por não terem desenvolvido ainda essa habilidade - que é adquirida pela prática - apresentam um entrave ao crescimento. Nesses países, observa-se dificuldade de entrosar as economias existentes com as oportunidades de investimento disponíveis.

$\mathrm{Na}$ verdade, o autor não se mostra satisfeito com as teorias existentes sobre os determinantes do investimento, apesar de ser a variável mais importante envolvida no processo de crescimento de um país ou região. Entretanto, também não se propõe a desenvolver ele próprio uma teoria. 
Segundo ele, ainda existe uma parte do investimento que não pode ser convincentemente explicada pelas variáveis econômicas. Nesse sentido, a teoria pós-Keynesiana tem uma contribuição fundamental. Exatamente essa parte "inexplicável" do investimento a que o autor se refere é determinada, segundo esses teóricos, pelas expectativas de longo prazo dos empresários. Contém, portanto, alto grau de subjetividade, uma vez que se relaciona a interpretações pessoais, estados de confiança e animal spirits. ${ }^{6}$

Para a construção de sua teoria do desenvolvimento, o autor parte do pressuposto de que o desequilíbrio é o elemento que move a economia. A necessidade de superação dos gargalos gerados pelo avanço desigual de um setor dá dinâmica ao processo de desenvolvimento. Portanto, a criação permanente de gargalos no sistema produtivo leva ao investimento induzido, que, segundo ele, é muito importante para o processo de industrialização dos países subdesenvolvidos. Nas palavras do autor:

A cada passo, uma indústria tira vantagem de economias externas criadas pela expansão prévia e, ao mesmo tempo, forma novas economias externas a serem exploradas por outros operadores (HIRSCHMAN, 1961, p. 108).

Essas economias externas são resultado do efeito completivo do investimento.

Essa teoria não prescinde da ação de forças externas ao mercado. Hirschman (1961) sugere que o setor público intervenha no caso de haver problemas de oferta no curso desigual do progresso dos setores - especialmente naquelas áreas onde o capital privado não atua (como infraestrutura de modo geral). O Estado deveria também planejar e coordenar todo o processo, buscando incentivar o desenvolvimento dos setores-chave da economia, quais sejam, aqueles que apresentam os maiores efeitos encadeadores (para frente e para trás).

O autor define duas possíveis estratégias de desenvolvimento:

1. Desenvolvimento via capacidade excessiva de capital social básico - CSB (infraestrutura, incluindo todos os serviços públicos e o capital geral agrícola). Esta estratégia baseia-se na expansão iniciada pelos acréscimos no suprimento de CSB. O autor supõe aqui que a capacidade excessiva de CSB atrai para o país ou região investidores nas atividades produtivas diretas, promovendo assim o seu desenvolvimento.

2. Desenvolvimento via escassez de CSB. A ideia aqui é a de que se a atividade produtiva direta passar à frente da CSB, fortes pres-

6 Expressão cunhada por Keynes para descrever o comportamento dos empresários frente às decisões de investimento. 
sões estabelecer-se-ão para a provisão da mesma, induzindo o desenvolvimento.

Ambas as formas estabelecem incentivos e pressões para novas inversões. A respectiva eficiência dependerá da força das motivações empreendedoras e da reação do governo (responsável pelas inversões em infraestrutura) à pressão pública.

$\mathrm{O}$ efeito das estratégias de desenvolvimento apontadas acima se deve à redução da incerteza, que se manifesta de forma muito mais forte nos países subdesenvolvidos. Apesar de o autor não invocar a teoria de Keynes - especificamente o pressuposto da não neutralidade da moeda para a construção do seu raciocínio, essa se ajusta perfeitamente à sua lógica. Segundo Hirschman (1961), antecipar a provisão de CSB, ou iniciar com investimentos nas atividades produtivas, gera um ambiente mais propício a novas inversões, por reduzir a incerteza (especialmente com relação à demanda). Esse fato, de acordo com os pós-Keynesianos, diminui a preferência pela liquidez dos agentes, implicando a realização de novas inversões na economia, que é exatamente o efeito esperado por Hirschman.

\subsubsection{Gunnar Myrdal}

Esse autor, assim como Hirschman (1961), apresentou críticas em relação à Teoria do Desenvolvimento Equilibrado. Segundo ele, a principal delas é a dificuldade que existe para se construir uma política industrial madura e equilibrada. Os países subdesenvolvidos, por definição, têm estrutura desequilibrada e o equilíbrio dessa não deve ser um fim. $\mathrm{O}$ objetivo deve ser o de atingir o desenvolvimento a partir de um processo de industrialização impulsionada por desequilíbrios (MYRDAL, 1960).

A contribuição essencial de Myrdal (1960) está relacionada ao enfoque dado à dinâmica centro versus periferia. Segundo o autor, para entender o subdesenvolvimento de um país é preciso inseri-lo nesse contexto. A partir dessa ótica, o desenvolvimento nunca será igual entre as regiões - ele é desequilibrado pois visa o favorecimento das economias mais desenvolvidas.

Para descrever o processo de reprodução contínua da dicotomia centro-periferia, Myrdal (1960) desenvolveu o princípio da causação circular acumulativa. Esse foi elaborado a partir de um estudo sobre o problema dos negros nos EUA (racismo). Nesse estudo, identificou que a essência do problema social envolve um complexo de mudanças interdependentes circulares e acumulativas. Daí observou ser a teoria do equilíbrio insatisfatória. Segundo o autor, o processo acumulativo, quando não controlado, promoverá desigualdades crescentes.

Trazendo essa ideia para o âmbito da economia, Myrdal (1960) conclui que há tendência inerente ao processo de desenvolvimento, que é a 
promoção de desigualdades econômicas e regionais em um país. Dessa forma, opõe-se à teoria da convergência.

Segundo o autor, o processo de expansão cria economias externas favoráveis à sua continuidade. Por outro lado, a expansão em uma determinada região produz efeitos regressivos em outras. A migração, o movimento de capital e o comércio são os meios pelos quais o processo acumulativo se desenvolve - para cima, nas regiões desenvolvidas, e para baixo, nas mais pobres.

Em oposição aos efeitos regressivos, há os propulsores, que são transmitidos do centro de expansão econômica para outras regiões. Esses afetam tanto as localidades vizinhas da região que se está desenvolvendo, como também aqueles locais que suprem as indústrias em desenvolvimento (ainda que distantes).

Quanto mais alto o nível de desenvolvimento de um país, mais fortes serão os efeitos propulsores. Tal fato tende a conter o impulso para a promoção das desigualdades regionais. Dessa forma, o progresso econômico não só é mantido, como é também reforçado. Em um país subdesenvolvido, entretanto, tais efeitos propulsores são fracos. As forças competitivas do mercado tenderão, assim, a promover constantemente disparidades regionais, em causação circular. Isso acabará por desestimular o próprio desenvolvimento econômico nessas regiões. Esse é um dos motivos pelo qual se diz que "a pobreza é a causa da própria pobreza".

Myrdal (1960) considera em seu trabalho que a moeda exerce um importante papel nesse processo acumulativo. Segundo o autor, estudos em muitos países revelam que o sistema bancário pode se transformar em um instrumento que drena as poupanças das regiões mais pobres para aquelas mais ricas e prósperas, onde se tem uma remuneração do capital mais alta e mais segura.

Pode-se dizer que tal fato se deve à menor disposição tanto dos bancos de ofertarem crédito nas regiões periféricas, como aos agentes em realizarem suas inversões nessas regiões. Ou seja, reflete a maior preferência pela liquidez dos agentes locais.

Conclui-se com o autor, que a incerteza presente de forma mais acentuada nas regiões pobres contribui para aumentar nessas a preferência pela liquidez dos agentes, levando, em última instância, por meio do processo acumulativo, ao menor grau de desenvolvimento.

Para frear esse processo acumulativo negativo, é fundamental que haja mudanças compensatórias, como, por exemplo, deseconomias externas e reversão de expectativas. O Estado pode exercer um importante papel nesse sentido, ao tentar propiciar a redução da incerteza presente no ambiente econômico.

Vale ressaltar que, em seu estudo, Myrdal (1960) refuta a lei de Say e admite que a postura Keynesiana frente a esse tópico seria a mais realista. 
Enquanto os estudiosos neoclássicos continuavam a admitir validade da lei de equilíbrio entre oferta e demanda globais (lei de Say), os empresários, bancos e partidários do governo - antecipando-se ao desenvolvimento teórico de Keynes - sempre acreditaram que a demanda poderia, de fato, cair aquém da oferta ou excedê-la. E suas ações eram pautadas por essa crença.

\section{Contribuição para o Debate sobre o Desenvolvimento Desigual}

Independentemente de ser ou não incorporada na discussão sobre o desenvolvimento desigual entre as regiões ou países, a observação empírica sustenta a crença de que, em uma sociedade capitalista, a moeda é capaz de afetar de forma permanente o processo de acumulação da economia. ${ }^{7}$

Existem diversas referências dispersas na literatura recente sobre $\mathrm{o}$ papel da moeda no desenvolvimento desigual das regiões. Essas, porém, não foram elaboradas como teorias de desenvolvimento. Entretanto, é importante que elas sejam incorporadas no debate a fim de tentar colaborar para o seu avanço. Abaixo serão apresentadas algumas contribuições fundamentais para o tema, sem pretender, no entanto, esgotá-las.

Dow $(1982 ; 1987)$ foi pioneira em introduzir o referencial pós-Keynesiano na análise da dinâmica espacial. De acordo com a autora, ainda que Keynes tenha enfatizado a importância da moeda no âmbito nacional, sua relevância não foi transportada para o nível regional; existe pouca referência para o papel da moeda nesse contexto.

A partir dos conceitos teóricos pós-keynesianos e utilizando-se de elementos da Teoria da Causação Cumulativa e da Dependência, a autora apresentou modelos em que o sistema financeiro, juntamente com o lado real da economia, pode fomentar padrões de desenvolvimento regional desiguais.

A autora conclui que existe uma tendência, inerente ao sistema financeiro, de se concentrar em determinados locais, notadamente nos centros financeiros mais desenvolvidos. A tendência relaciona-se à capacidade de os bancos localizados nestes centros inspirarem maior confiança nos agentes econômicos e, portanto, gerarem mais crescimento e lucros. Assim, tem-se que: mais confiança implica mais negócios e maior capacidade de alcançar economias de escala, que inspiram ainda mais confiança e assim por diante.

Amado (1997) analisou a dinâmica financeira regional no Brasil, também partindo da abordagem pós-keynesiana de incerteza, tempo e

7 Ver, por exemplo, os estudos de Amado (1997), Crocco et al. (2003), Cavalcante, Crocco, Jayme Jr. (2006) e Crocco et al. (2006), para o caso brasileiro, e Dow (1993), para um caso mais geral. 
moeda e baseada no trabalho pioneiro de Dow. Concluiu que as diferenças estruturais profundas, observadas entre as diversas regiões no País, conduzem a uma dinâmica monetária que tende a ampliar as desigualdades, ao invés de reduzi-las, como prevêem os modelos ortodoxos. Dadas as características estruturais das regiões periféricas e suas relações com as economias centrais, Amado observou que o comportamento privado dos agentes acaba por gerar círculos viciosos, que não dizem respeito às variáveis reais apenas. De fato, esses círculos têm rebatimentos financeiros e mesmo têm parte de suas fontes nas relações dos próprios agentes com a moeda.

Crocco et al. (2003), seguindo a mesma linha de pensamento, testaram o impacto do acesso bancário e da preferência pela liquidez do público sobre o desenvolvimento econômico mineiro. O trabalho concluiu que, de fato, as regiões do estado com menor acesso aos bancos e maior preferência pela liquidez dos agentes sofrem de restrição de crédito, tendo, portanto, o seu desenvolvimento dificultado. Tais regiões são exatamente as mais pobres em termos de bens e serviços. Dessa forma, as características econômicas e sociais induziriam a fatores institucionais que, ao inibirem a geração de crédito, desestimulariam o crescimento econômico, contribuindo para a manutenção das características iniciais.

Em 2004, Cavalcante, Crocco e Jayme Júnior analisaram empiricamente algumas hipóteses do pensamento pós-keynesiano acerca da distribuição do crédito regionalmente, salientando a importância da moeda na economia regional. Estimaram a preferência da liquidez do público e dos bancos dos diferentes estados brasileiros. Concluíram que, devido aos distintos graus de incerteza presentes em cada região, graças às suas condições econômicas diferenciadas, a demanda e a oferta de moeda seriam menores nos locais menos desenvolvidos do que aquelas observadas nos mais desenvolvidos, refletindo as distintas preferências pela liquidez do público e dos bancos.

Em um trabalho posterior, Crocco et al. (2005-2006) demonstraram que a centralidade, ${ }^{8}$ que pode ser considerada um importante determinante do desenvolvimento desigual das regiões, é influenciada pelo comportamento das variáveis financeiras.

De acordo com os autores, uma maior centralidade leva a uma maior diversificação dos setores secundário e terciário. Essa amplia as alterna-

$8 \quad$ O conceito de centralidade foi desenvolvido por Christäller (1966) referindo-se à importância relativa de um lugar com respeito à região do seu entorno. Os bens e serviços centrais são aqueles necessariamente produzidos e ofertados em poucos pontos centrais de forma a serem consumidos em muitos pontos dispersos. Quanto mais especializados forem os bens e serviços, mais concentrados em poucos centros eles serão, ou, de acordo com a caracterização adotada por Christäller, maior será a ordem hierárquica desses centros (maior a centralidade, então). 
tivas de investimento dos bancos ao possibilitar a diversificação de suas carteiras. Com isso, observa-se uma redução na preferência pela liquidez dos mesmos. Os empresários, por outro lado, também têm reduzida a sua preferência pela liquidez. A maior diversificação, propiciada pela maior centralidade, gera externalidades que podem ser apropriadas pelas firmas, atenuando a incerteza no local. Assim, regiões mais centrais tendem a desenvolver-se ainda mais.

A abordagem pós-keynesiana ajuda no entendimento da dinâmica da acumulação capitalista no âmbito local e regional. De acordo com essa linha de pensamento, as diferenças estruturais existentes entre as diversas regiões de um país, ou entre os diversos países, levam a um círculo vicioso (com relação às variáveis reais e monetárias) que tende a ampliar/ perpetuar as desigualdades, ao invés de reduzi-las, como prevêem os modelos ortodoxos. Resumidamente, tem-se que nos locais mais atrasados (periferia), a incerteza é maior, consequentemente a disponibilidade de crédito é menor (devido à maior preferência pela liquidez dos diversos agentes econômicos), o que leva a um nível de investimento mais reduzido. Com isso, amplia-se a incerteza nessas regiões, desestimulando ainda mais o investimento e assim por diante. O contrário ocorre nas áreas mais desenvolvidas (DOW, 1993).

Pode-se constatar, juntamente com os autores citados acima, que a moeda de fato exerce papel relevante na determinação da renda e do emprego, podendo ser responsável pela manutenção e ampliação das diferenças regionais, ou seja, interfere diretamente no processo de desenvolvimento de um país ou região.

\section{Considerações Finais}

Explicar a diversidade do desempenho econômico entre os países e/ ou regiões constitui o maior desafio dos teóricos do desenvolvimento desigual. Apesar de existirem pontos comuns nas teorias desenvolvidas pelos mesmos, elas dividem-se em duas grandes vertentes que levam a diferentes conclusões acerca do caminho que um país ou região deve seguir a fim de alcançar um estágio mais avançado para sua economia: a do crescimento equilibrado e a do crescimento desequilibrado.

Pode-se constatar que, apesar de as teorias apresentadas aqui não explicitarem o papel da moeda no processo de desenvolvimento de um país ou região, a maior parte delas o fazem implicitamente ao introduzirem a incerteza como fator fundamental na determinação do comportamento dos agentes, na decisão do investimento. Num mundo no qual o futuro é desconhecido e incerto, os agentes preferem reter moeda e, por conseguinte, suas decisões de gastos, sejam de consumo, sejam de 
investimento, são postergadas. Essa possibilidade de retenção de moeda acaba por condicionar a dinâmica do processo produtivo. A não neutralidade da moeda diz respeito exatamente à compreensão do processo de decisão dos indivíduos em um contexto de incerteza. O único autor que desconsidera a importância das variáveis monetárias é Ragnar Nurske, que possui claramente um viés clássico.

Conforme exposto no item 4 deste trabalho, existem diversos estudos recentes que evidenciam a não neutralidade, o papel central e a importância da moeda no processo decisório dos agentes econômicos. Com base nesse pressuposto, conclui-se que o fato de se ignorar a influência da moeda pode levar a consequências desastrosas em termos de estratégias de desenvolvimento adotadas pelos países e regiões.

Assim, ainda que parte dos teóricos do desenvolvimento desigual incorpore implicitamente a não neutralidade da moeda em seus estudos, seria interessante que o fizessem explicitamente. Dessa forma, trazendo a questão para o centro da discussão poder-se-ia aprofundar a análise, abrindo caminho não só para o melhor entendimento do processo de crescimento desigual como também para a elaboração de estratégias para o desenvolvimento. Isso concorreria grandemente para o avanço do debate.

\section{Referências}

AMADO, A. M. A questão regional e o sistema financeiro no Brasil: uma interpretação pós-keynesiana. Estudos econômicos, v. 27, n. 3, p. 417-440, 1997.

CARVALHO, F. C. Mr Keynes and the post Keynesians: Principles of macroeconomics for a monetary production economy. Edward Elgar: Aldershot, 1992.

CAVALCANTE, A.; CROCCO, M. A.; JAYME JR, F. G. Preferência pela liquidez, sistema bancário e disponibilidade de crédito regional. In: CROCCO, M. A.; JAYME JR, F. G. (Org.). Moeda e território: uma interpretação da dinâmica regional brasileira. Belo Horizonte: Autêntica Editora, 2006. p. 295-315.

CHRISTALLER, W. Central Places in Southern Germany. New Jersey: Prentice-Hall, 1966. CROCCO, M. A. Uncertainty, technical change and effective demand. Ph.D. Thesis, University of London, 1999.

. Innovation and social probable knowledge. Cambridge Journal of Economics, v. 27, n. 2, p. 177-190, 2003.

CROCCO, M. A. et al. Desenvolvimento econômico, preferência pela liquidez e acesso bancário: um estudo de caso. Belo Horizonte: UFMG/CEDEPLAR, maio de 2003 (Texto para discussão n. $^{\circ}$ 192).

CROCCO, M. A. et al. The behaviour of liquidity preference of banks and public and regional development: the case of Brazil. Journal of Post Keynesian Economics, v. 28, n. 2, p. 217-40, Winter 2005-2006.

CROCCO, M. A. et al. Polarização regional e sistema financeiro. In: CROCCO, M. A.; JAYME 
JR, F. G. (Org.) Moeda e território: uma interpretação da dinâmica regional brasileira. Belo Horizonte: Autêntica Editora, 2006. p. 231-269.

DAVIDSON, P. Rational Expectations: A fallacious foundation for studying crucial decisionmaking processes. Journal of Post Keynesian Economics, v. 5, n. 2, p. 182-196, Winter 1982-1983.

Uncertainty in economics. In: DOW, S. and HILLARD, J. (eds.). Keynes, knowledge and uncertainty. Aldershot, UK: Edward Elgar, 1995. p. 107-116.

DOW, S. The regional composition of the money multiplier process. Scottish Journal of Political Economy. v. 19, n. 1, 1982.

The treatment of money in regional economics. In: DOW, S. (ed.). Money and the economic process. Aldershot: Elgar, 1987.

. Money and the economic process. Aldershot: Edward Elgar, 1993.

. Uncertainty about uncertainty. In: DOW, S.; HILLARD, J. (eds.). Keynes, knowledge and uncertainty. Aldershot, UK: Edward Elgar, 1995, p. 117-136.

DOW, S. E RODRÍGUES-FUENTES, C. EMU and the regional impact of monetary policy. Regional Studies. v. 37, n. 9, p. 969-980, Dec. 2003.

FEIJÓ, C. A. Decisões empresariais em uma economia monetária de produção. In: LIMA, G. T.; SICSU, J. e PAULA, L. F. (Org.) Macroeconomia Moderna: Keynes e a economia contemporânea. Rio de Janeiro: Campus, 1999, p. 109-132.

HIRSCHMAN, A. A estratégia de desenvolvimento econômico. Rio de Janeiro: Fundo de Cultura, 1961, caps. 2, 3, 4, 5 e 10.

KEYNES, J. M. The ex-ante theory of the rate of interest. In: The general theory and after. Part II: defence and development. Cambridge: Macmillan, 1971a. (The Collected Writings of John Maynard Keynes, XIV).

. Alternative theories of the rate of interest. In: The general theory and after. Part II: defence and development. Cambridge: Macmillan, 1971b. (The Collected Writings of John Maynard Keynes, XIV).

Mr. Keynes' finance. In: The general theory and after. Part II: defence and development. Cambridge: Macmillan, 1971c. (The Collected Writings of John Maynard Keynes, XIV).

LEMOS, M. B. Espaço e capital: um estudo sobre a dinâmica centro x periferia. (Tese de doutorado em economia) Campinas: UNICAMP, 1988, cap. 5.

MYRDAL, G. Teoria econômica e regiões subdesenvolvidas. Rio de Janeiro: ISEB, 1960, caps. 2 , 3 e 4.

MOLLO, M. L. R. Moeda, taxa de juro e preferencia pela liquidez em Marx e Keynes. In: LIMA, G. T. e SICSU, J. (Org.) Macroeconomia do emprego e da renda: Keynes e o Keynesianismo, Sao Paulo: Manole, 2003, p. 451-498.

NURSKE, R. Problems of capital formation in underdeveloped countries. Oxford: Basil Blackwell, 1955, cap.1.

ROSENSTEIN-RODAN, P. Problems of industrialization of Eastern and South-Eastern Europe. Economic Journal, 53 (3), 1943.

Recebido em: 09/09/2008.

Aceito em: 17/10/2008. 